
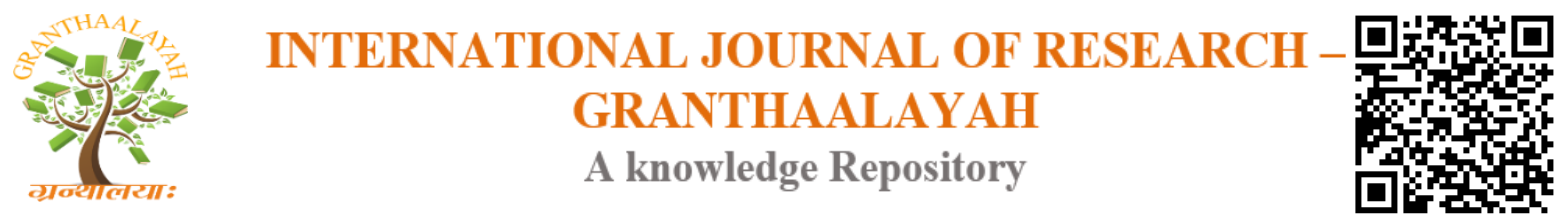

Science

\title{
CHARACTERIZATION AND DETECTION OF NORMAL LIVER TEXTURE USING ULTRASOUND
}

\author{
Ashraf Mustafa ${ }^{\text {, }}$ Mohamad Elfadil Mohamed Gar Elnabi ${ }^{2}$, Mona Ahmed ${ }^{3}$, \\ Abdelmoneim Sulieman 1, *2 \\ ${ }^{1}$ College of Medical Radiologic Science, Sudan University of Science and Technology, P.O. \\ Box 1908, Khartoum 11111, Sudan \\ ${ }^{2}$ Prince Sattam bin Abdulaziz University, College of Applied Medical Sciences, Alkharj, Saudi \\ Arabia
}

\begin{abstract}
The main research conducted to know the importance of duplex Ultrasonography in the control, follow-up \& the diagnosis of the different types of liver post-transplantation problems. Three hundred normal liver Doppler scan done to be as a reference (liver span and echotexure by the naked eye; not by image processing programme - IPP; in young expected normal patients in relation to normal liver transplanted patients- not a diseased liver, cirrhosis or hepatitis) to the Sudanese normal livers before starting the research, and about 65 Sudanese patients found with liver transplantations from them only 45 were available for liver Doppler scan. The data had been collected from the 300 normal objects population are the students of faculty of medicine in Al Rabat University (ages between 16-22 yrs., $48 \% \mathrm{M} ; 52 \% \mathrm{~F}$ ); the study done during the period from 1st April 2016 to 30th July 2017. The liver span is in the range $(9.5-13.9 \mathrm{~cm})$, the majority is of homogenous echo - level grading. The Statistical Package for Social Science - SPSS version 20.0 is used; no significant difference found between young males and females, however, that the upper limit of the liver span is a little bit more than the international values.
\end{abstract}

Keywords: Liver Texture; Liver Span; Ultrasonography.

Cite This Article: Ashraf Mustafa, Mohamad Elfadil Mohamed Gar Elnabi, Mona Ahmed, and Abdelmoneim Sulieman. (2018). "CHARACTERIZATION AND DETECTION OF NORMAL LIVER TEXTURE USING ULTRASOUND." International Journal of Research - Granthaalayah, 6(11), 427-430. https://doi.org/10.29121/granthaalayah.v6.111.2018.1148.

\section{Introduction}

The liver is the body's largest internal organ, weighing about 3 pounds $(1.5 \mathrm{~kg})$ in adults. It is located below the diaphragm on the right side of the abdomen (the right upper quadrant). The Couinaud system divides the liver vertically along the planes of the hepatic veins and horizontally along the planes of the left and right portal veins. Understanding of this anatomy is critical for surgical planning in liver resection and living related donation. These divisions named as lobes 
(right; left; caudate; caudate) which further has been divided into segments (1-9 segments). The liver performs many complex functions in the body. It produces most proteins needed by the body; it metabolizes and breaks down nutrients from food to produce energy, when needed. The liver prevents shortages of nutrients by storing certain vitamins, minerals and sugars. It also produces bile, a compound needed to digest fat and to absorb vitamins $\mathrm{A}, \mathrm{D}, \mathrm{E}$ and $\mathrm{K}$, produces most of the substances that regulate blood clotting. In addition it helps the body to fight infection by removing bacteria from the blood, and removes potentially toxic products of certain medications.

Objectives: The main objective of this study was to put a relative national index (in Sudan) for the liver size (span) \& echotexure, relate this with international values, and also in the future to relate it with the livers of patients with liver failure as well as those which are planned for or did transplantation.

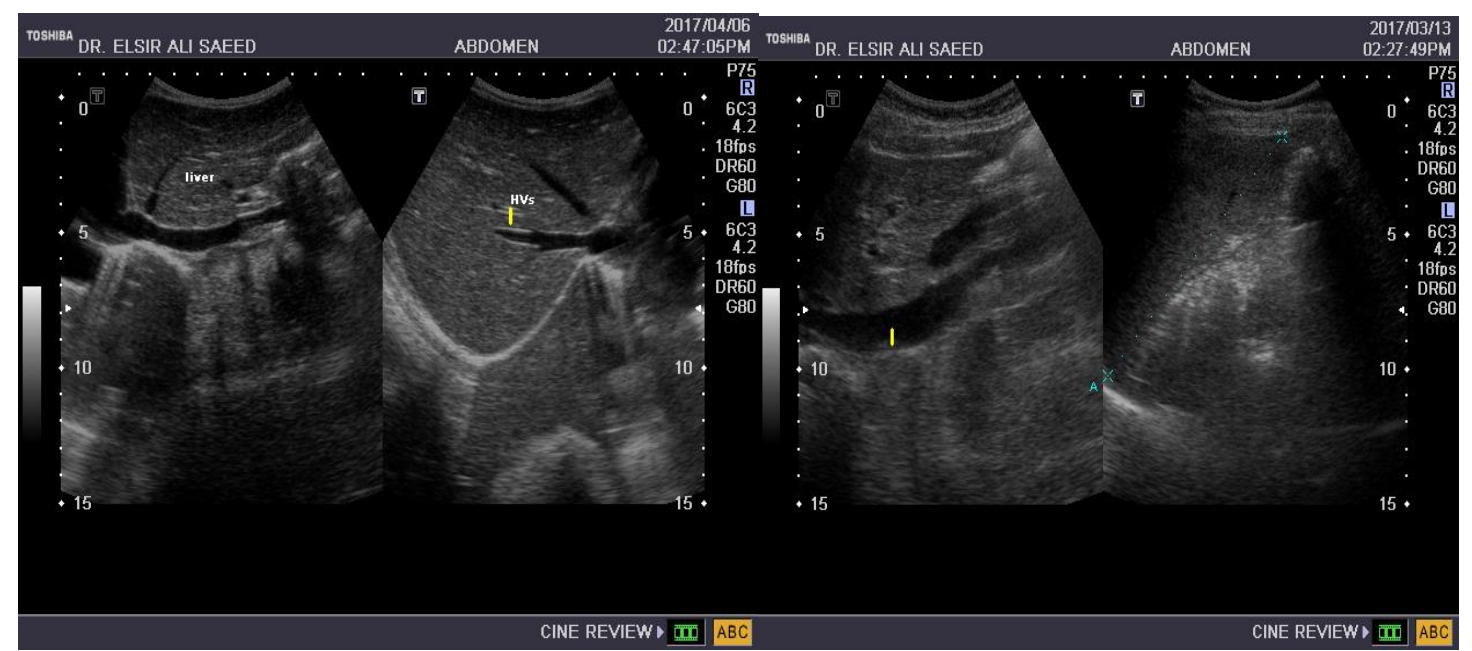

Image 1: Liver span \& echotexture

\section{Materials and Methods}

Methods of data collection: using the data sheet, we perform both transverse and longitudinal techniques plus coronal oblique; putting the transducer in the mid-line, mid clavicular line, anterior and mid axillary lines intercostally in points that made with a perpendicular imaginary line from the xiphisternum. In addition, sub costal scan done in the same points.

\section{Sample Size}

The data had been collected from 300 objects; population: students of faculty of medicine in Al Rabat University (ages between 18-22 yrs., 48 M; 52\% F).

\section{Equipment}

- Couch; pillow; bed sheet; cover; sterile gloves; acoustic gel.

- Two ultrasound machine of complete capabilities (ALOKA prosound; SSD-3500SX and TOSHIBA US SYSTEM); with two probes (curvilinear $=3.5-5 \mathrm{MHz} \&$ linear=7.5 -10 $\mathrm{MHz})$. 


\section{Results and Discussions}

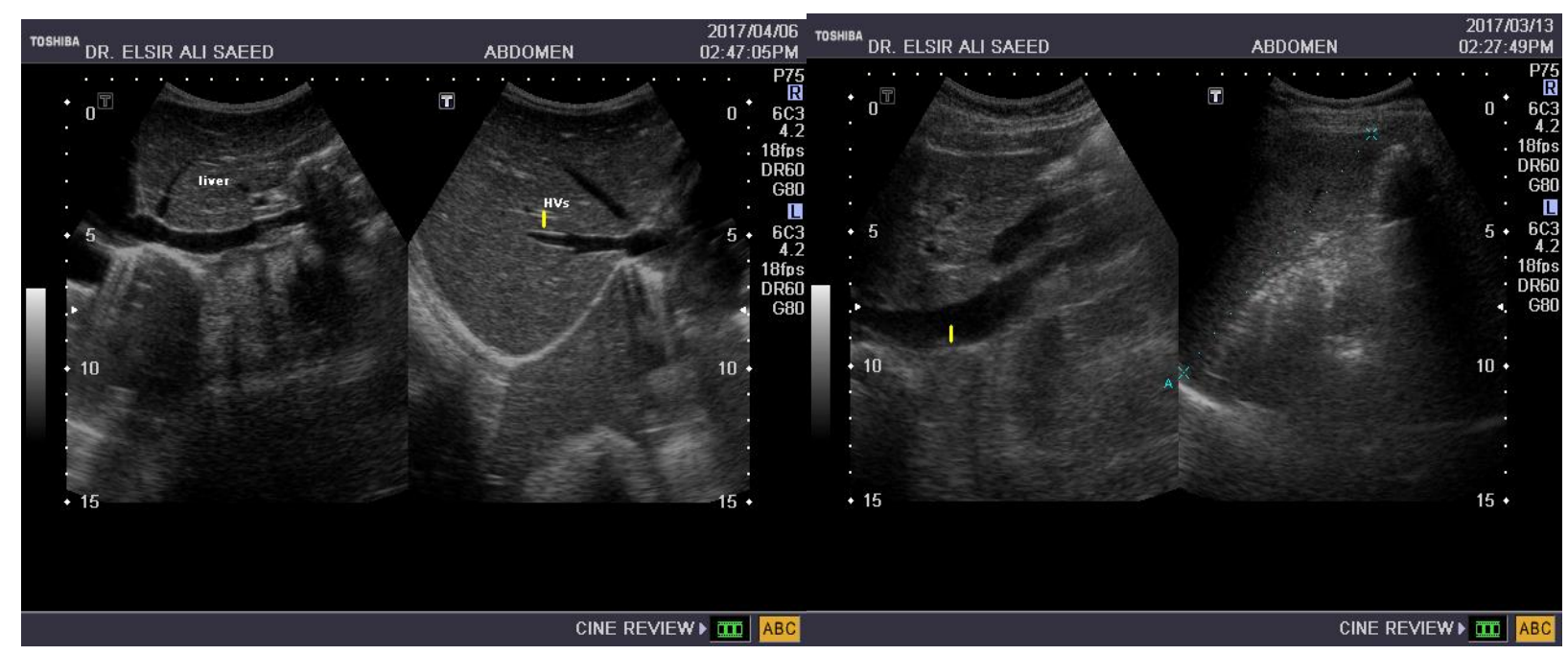

The data was collected from the three hundred young expected normal student of faculty of medicine in Al Rabat University during the period from 1st April 2016 to 30th July 2017, and it is analyzed using the Statistical Package for Social Science - SPSS version 20.0. The ages was found to be between 16-22 yrs. (48\% of them are males; $52 \%$ are Females).

The following table and figure show that the ages of the selected objects between 16-22 years; by this we evaluate young livers

\begin{tabular}{|l|l|l|l|}
\hline variables & Mean \pm SD & min & $\max$ \\
\hline Age $($ yrs.) & & 16 & 22 \\
\hline Liver Span $(\mathrm{cm})$ & & 9.5 & 13.9 \\
\hline
\end{tabular}

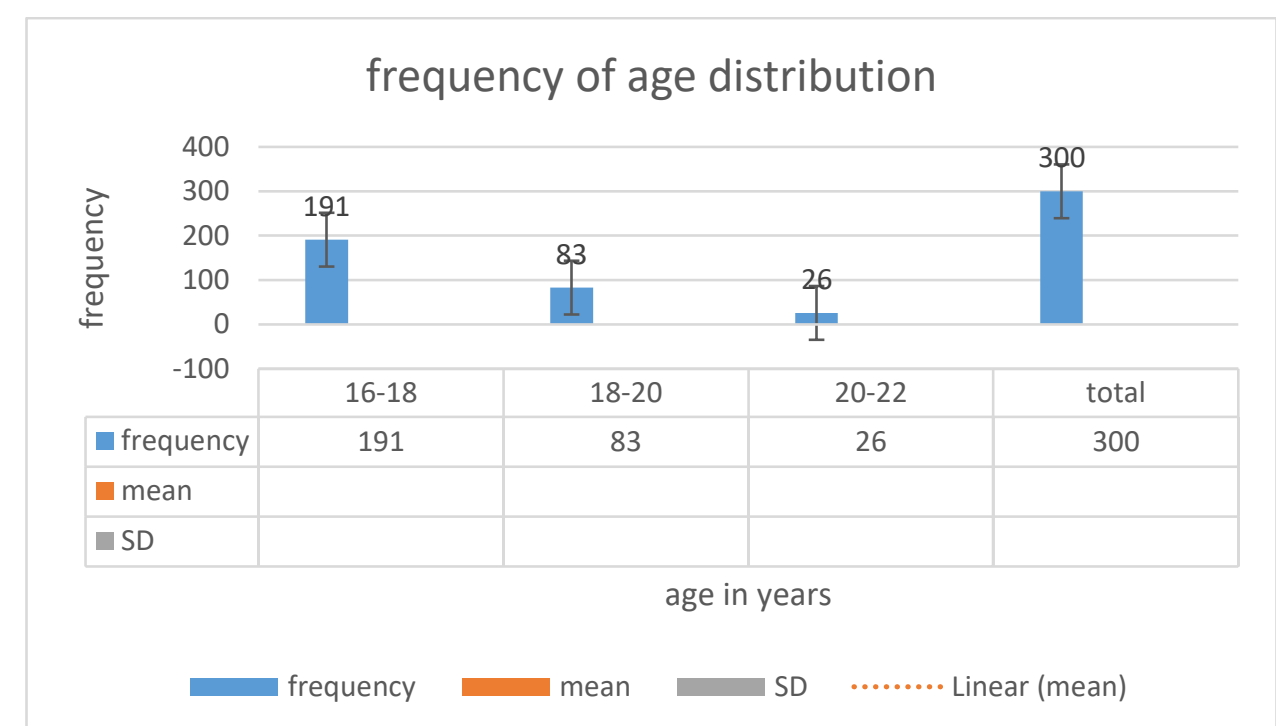

Figure 1: bar chart shows the age distribution, where the age group (16-18) is the majority. 


\section{Conclusions and Recommendations}

No national normal values are documented; the international studies show that the normal liver span ranges approximately $(10-12.5 \mathrm{~cm})$, anterior to posterior; measurement taken at mid clavicular in longitudinal section. Itis found that the Sudanese liver volume as well as texture similar in the previous international studies plus increased upper limit, and our study confirm these results. The liver span is in the range $(9.5-13.9 \mathrm{~cm})$, the majority are of homogenous echo - level grading. No significant difference found between young males and females, however, that the upper limit of the liver span is a little bit more than the international values by about $1.4 \mathrm{~cm}$.

\section{References}

[1] Desser TS, Sze DY, Jeffrey RB. Imaging and intervention in the hepatic veins. AJR Am J Roentgenol 80(6):2003, 1583-1591.

[2] Marks WM, Filly RA, Callen PW. Ultrasonic anatomy of the liver: a review with new applications. J Clin Ultrasound 7:1979137- 146.

[3] Skandalakis JE, Skandalakis LJ, SkandalakisPN,Mirilas P. Hepatic surgical anatomy. SurgClin North Am 84(2):20014, 413-435.

[4] Sugarbaker PH. Toward a standard of nomenclature for surgical anatomy of the liver. Neth J Surg 1988; PO:100.

[5] Nelson RC, Chezmar JL, Sugarbaker PH, et al. Preoperative localiza -tion of focal liver lesions to specific liver segments: utility of CT during arterial portography. Radiology 176:1990, 89-94.

[6] Soyer P, Bluemke DA, Bliss DF, et al. Surgical segmental anatomy of the liver: demonstration with spiral CT during arterial portogra -phy and multiplanar reconstruction. AJR Am J Roentgenol 163: 1994; 99-103.

[7] Lafortune M, Madore F, Patriquin H, Breton G. Segmental anatomy of the liver: a sonographic approach to the Couinaud nomenclature. Radiology 1991; 181:443-448.

[8] Gosink BB, Leymaster CE. Ultrasonic determination of Hepatomegally. J Clin Ultrasound;9: 198137-44.

[9] Niederau C, Sonnenberg A, Muller JE, et al. Sonographic measurements of the normal liver, spleen, pancreas, and portal vein. Radiology;149: 1983537-540.

[10] Zhuang ZG, Qian LJ, Gong HX, et al. Multidetector computed tomography angiography in the evaluation of potential living donors for liver transplantation: single-center experience in China. Transplant Proc;40(8): 20082466-2477.

[11] Erbay N, Raptopoulos V, Pomfret EA, Kamel IR, Kruskal JB. Living donor liver transplantation in adults: vascular variants important in surgical planning for donors and recipients. AJR Am J Roentgenol;181(1): 2003109-114.

\footnotetext{
*Corresponding author.

E-mail address: abdelmoneim_a@yahoo.com
} 